\title{
PRELIMINARY STUDY OF INSECT ATTRACTION BY A MIXTURE OF SEMIOCHEMICALS CONTAINING 1,2,4-TRIMETHOXYBENZENE IN DOMESTIC CITRIC-CULTURE
}

\author{
Ana Paula L. Alves, José Augusto B. de C. Júnior, Glaucia B. A. Slana, Jari N. Cardoso, Rosangela S. C. Lopes e Claudio \\ C. Lopes* \\ Departamento de Química Analítica, Instituto de Química, Universidade Federal do Rio de Janeiro, CT, Bl. A, 21949-900 Rio de \\ Janeiro - RJ, Brasil
}

Recebido em 17/6/08; aceito em 12/8/09; publicado na web em 11/1/10

\begin{abstract}
In this work we describe a new efficient strategy for the preparation of 1,2,4-trimethoxybenzene (3) in $56 \%$ overall yield. The compound $\mathbf{3}$ was used in a preliminary study of insect attraction by a mixture of semiochemicals called TIV, composed of indol (1), vanillin (2) and 1,2,4-trimethoxybenzene (3), in eight Mc Phail style traps installed at a domestic orchard of citric-culture, containing 120 trees not infected by plagues in Bom Jesus Farm, located next to a patch of the Atlantic Forest, at Silva Jardim, Rio de Janeiro, Brazil.
\end{abstract}

Keywords: Euglossini bees, 1,2,4-trimethoxybenzene, semiochemicals.

\section{INTRODUCTION}

One of the most known application of insect semiochemicals is in the undesirable effects of pest on agriculture. Much of the behavior of insect pests is associated with the search for food, sexual partners and egg-laying sites, together with defensive activities to protect them from adverse environmental conditions and natural enemies. ${ }^{1}$ The study of semiochemicals that influence insect behavior is a promising method for pest control as alternative to the exclusive use of broad-spectrum toxicants. ${ }^{2}$ Those compounds, called pesticides, have detrimental effects of on health, environment and organisms.

Employing insect attractants in agricultural crops represent an important alternative strategy for insect control, because pest can be attracted and be mass trapped. In this way it is possible to improve not only food quality but also life quality.

Last but not least, insect attractants have a potential application in flower pollinization. Many flowers have naturally bad pollinization due to unfavorable sexual structures anatomy. That is the case of Passiflora alata. The semiochemical, in these cases, may attract the pollinators, increasing the population of those insects where they are required.

On previous work, Ventura and coworkers studied the relative responses of Diabrotica speciosa (Ger.) and Cerotoma arcuata tingomariana on fields of common bean and soybean using traps baited with 1,4-dimethoxybenzene and also containing mixtures of semiochemicals such as VIP (veratrole+indol+phenylacetaldehyde) and TIC (1,2,4-trimethoxybenzene+indol+trans-cinnamaldehyde). ${ }^{3}$

The aim of this work is to evaluate the ability of a mixture of semiochemicals, called TIV (1,2,4-trimethoxybenzene, indol and vanillin), in attract insects of a productive citrous orchard, in Silva Jardim, at Rio de Janeiro, Brazil. For the preparation of TIV mixture, we have proposed a new low cost synthesis route of 1,2,4-trimethoxybenzene.

\section{EXPERIMENTAL}

\section{General methods}

All solvents and reagents were purchased from Vetec, Aldrich, Merck, Grupo Química, Isotec Inc. and Acros Organics. All solvents

*e-mail: claudiosabbatini@uol.com.br were dried and purified prior to use. ${ }^{4}$ All reactions were performed under anhydrous conditions. They were conducted in oven-dried glassware under an argon atmosphere. Air-sensitive solutions were transferred via oven-dried syringe needles under positive pressure of argon.

IR spectra were recorded on Magma IR-760-Nicolet spectrometer. FT IR spectra were taken in $\mathrm{KBr}$ and absorptions are reported in $\mathrm{cm}^{-1}$.

Proton $\left({ }^{1} \mathrm{H}\right)$ and carbon $\left({ }^{13} \mathrm{C}\right)$ nuclear magnetic resonance spectra were recorded on Varian Gemini $200 \mathrm{MHz}$ or Brucker $300 \mathrm{MHz}$ spectrometers. FT NMR spectra were taken in $\mathrm{CDCl}_{3}$ or DMSO-d $\mathrm{d}_{6}$. Chemical shifts $(\delta)$ are reported relative to tetramethylsilane TMS $\left(\delta_{\mathrm{TMS}}=0\right)$ in parts per million and the coupling constants $(J)$ are reported in Hz. Regarding the multiplicity the following abbreviations were employed: s (singlet); d (dublet); dd (double dublet), dt (double triplet), q (quartet) and $\mathrm{m}$ (multiplet).

High-resolution mass spectra were taken on an Atlas MS-12, Consolidated 12-110 B, and Finnegan 400 mass spectrometers at 70 $\mathrm{eV}$ at the University of California (Berkeley). Where mass spectral data are given, the peak value is immediately followed by its relative abundance in parentheses.

Melting points were recorded on a Mel-TempII capillary melting point apparatus and the temperatures were reported in ${ }^{\circ} \mathrm{C}$.

\section{Chromatography}

All reactions were followed by thin layer chromatography (TLC), under $0.2 \mathrm{~mm}$ silica gel $60 \mathrm{~F}_{254}$ plates (Merck). Plates were visualized with 2,4-dinitrophenylhydrazine, $p$-anisaldehyde, iron chrloride solutions stain ${ }^{5}$ or UV light.

In cases where a product was purified by silica gel column chromatography, packing material for flash chromatography ${ }^{6}$ was Merck silica gel 60 (230-400 mesh ASTM Merck).

The volatiles adsorbed at $\operatorname{Tenax}^{\circledR}$ resin (Aldrich), in the preliminary study of the volatilization of TIV mixture in laboratory, were analyzed on a Varian CP 3380 GC-FID and on a HP6890/5973N (Mass Selective Detector) - Agilent Tecnologies GC-MS.

The following conditions were performed on the GC-FID analysis: the TIV mixture was dissolved in EtOAc and subjected to a 30 $\mathrm{m} / 0.25 \mathrm{~mm}$ I.D. and $0.25 \mu \mathrm{m}$ film (column); split injection volume, $1 \mu \mathrm{L}$; injection temperature, $200{ }^{\circ} \mathrm{C}$; carrier gas - nitrogen; carrier 
flow, $1.0 \mathrm{~mL} / \mathrm{min}$; oven temperature program: $100{ }^{\circ} \mathrm{C}(3 \mathrm{~min}), 4{ }^{\circ} \mathrm{C} /$ min until $170{ }^{\circ} \mathrm{C}$; FID detector temperature: $300{ }^{\circ} \mathrm{C}$; total analysis time: $20.5 \mathrm{~min}$.

The following conditions were performed on the GC-MS analysis: the TIV mixture was dissolved in EtOAc and subjected to a 28.6 $\mathrm{m} / 0.25 \mathrm{~mm}$ I.D. and $0.3 \mu \mathrm{m}$ film (column); split injection volume, 1 $\mu \mathrm{L}$; injection temperature, $200{ }^{\circ} \mathrm{C}$; carrier gas - helium; carrier flow, $1.0 \mathrm{~mL} / \mathrm{min}$; oven temperature program: $80^{\circ} \mathrm{C}(3 \mathrm{~min}), 4{ }^{\circ} \mathrm{C} / \mathrm{min}$ until $170^{\circ} \mathrm{C}$; FID detector temperature: $230^{\circ} \mathrm{C}$; total analysis time: $25.5 \mathrm{~min}$.

\section{Field experiments}

Field experiments were carried out at Bom Jesus Farm, at BR 101, km 235, Silva Jardim, in the state of Rio de Janeiro in Brazil. The baited traps were placed in the field containing 120 of orange trees from the $1^{\text {st }}$ February 2004 until the $7^{\text {th }}$ February 2004, being removed after 7 days.

1,2,4-Trimethoxybenzene (3) used in this work was synthesized in our laboratory from vanillin (2). This compound and indol (1) were purchased from Vetec.

Eight traps with $300 \mathrm{mg}$ of TIV were fixed at $1.5 \mathrm{~m}$ height in orange trees. The mixture was used at a dosage of $100 \mathrm{mg}$ of each single chemical per trap. The same amount of control traps received no TIV. Distance between traps was at least $5 \mathrm{~m}$. The average temperature was $35^{\circ} \mathrm{C}$.

\section{Volatilization test in laboratory of TIV mixture}

TIV mixture was subjected to a volatile capture system where the carrier gas nitrogen cross a pre-drying tube before reaching the mixture in a three-neck round bottom flask. The volatiles are flowed towards Tenax ${ }^{\circledR}$ resin, where they are adsorbed.

A preliminary study of volatilization of TIV mixture in laboratory was carried out during 7 days. A blank was made without TIV mixture.

The sample resins were extracted with EtOAc and concentrated under low pression to be analyzed by GC-DIC and GC-MS apparatus.

\section{Synthesis of 1,2,4-Trimethoxybenzene (3) from Vanilin (2). Preparation of 3,4-Dimethoxybenzaldehyde (4)}

In a three-neck round bottom flask with a reflux condenser, a suspension of vanilin $(500 \mathrm{mg} ; 3.29 \mathrm{mmol})$ and $\mathrm{K}_{2} \mathrm{CO}_{3}(500 \mathrm{mg} ; 3.62$ mmol) in anhydrous $\mathrm{CH}_{3} \mathrm{COCH}_{3}(40 \mathrm{~mL})$ was stirred at $40-45^{\circ} \mathrm{C}$, under argonium atmosphere. After $1 \mathrm{~h}, \mathrm{CH}_{3} \mathrm{I}(716 \mathrm{mg} ; 0.32 \mathrm{~mL} ; 4.94$ mmol) was added dropwise and the resulting mixture was refluxed for $7 \mathrm{~h}$. The solvent was then removed under reduced pressure and the resulting solid was poured into $\mathrm{HCl} 5 \%(10 \mathrm{~mL})$, and extracted with EtOAc $(3 \times 20 \mathrm{~mL})$. The organic layer was then washed with brine, dried over $\mathrm{Na}_{2} \mathrm{SO}_{4}$, evaporated to dryness, and purified by silica gel chromatography (5-20\% EtOAc/hexanes) to yield 3,4-dimethoxybenzaldehyde (4) as a pale-yellow solid (518,75 mg; 95\%), mp 43-45 ${ }^{\circ} \mathrm{C}$; IR $\left(\mathrm{KBr}, \mathrm{cm}^{-1}\right): 3077,3019,2999,2920,2849,2765$ $(\mathrm{O}=\mathrm{C}-\mathrm{H}), 1686$ (C=O), $1275(\mathrm{C}-\mathrm{O}-\mathrm{C}), 1018$ (C-O-C), 802; ${ }^{1} \mathrm{H}$ NMR $\left(\mathrm{CDCl}_{3}, 200 \mathrm{MHz}\right) \delta: 9.84$ (s, 1H, COH), 7.48-7.39 (m, 2H, H-Ar), 6.97 (d, $J=8 \mathrm{~Hz}, 1 \mathrm{H}, \mathrm{H}-\mathrm{Ar}), 3.96$ (s, 3H, $\left.\mathrm{OCH}_{3}\right), 3.93$ (s, 3H, $\mathrm{OCH}_{3}$ ); ${ }^{13} \mathrm{C} \mathrm{NMR}\left(\mathrm{CDCl}_{3}, 50 \mathrm{MHz}\right) \delta: 191.0(\mathrm{C}=\mathrm{O}), 154.6\left(\mathrm{C}-\mathrm{OCH}_{3}\right), 149.7$ $\left(\mathrm{C}-\mathrm{OCH}_{3}\right), 130.2(\mathrm{C}-\mathrm{CHO}), 127.0\left(\mathrm{H}_{-} \mathrm{C}_{\mathrm{ar}}\right), 110.5\left(\mathrm{H}-\mathrm{C}_{\mathrm{ar}}\right), 109.0(\mathrm{H}-$ $\left.\mathrm{C}_{\mathrm{ar}}\right), 56.3\left(\mathrm{OCH}_{3}\right), 56.1\left(\mathrm{OCH}_{3}\right)$.

\section{Preparation of 3,4-Dimethoxyphenol (6)}

In a three-neck round bottom flask with a reflux condenser, $m$ CBPA 70\% (3.61 g; $20.0 \mathrm{mmol})$ and $\mathrm{NaHCO}_{3}(0.58 \mathrm{~g} ; 7.0 \mathrm{mmol})$ were added to a stirring solution of 3,4-dimethoxybenzaldehyde (4) $(1.66 \mathrm{~g} ; 10.0 \mathrm{mmol})$ in anhydrous $\mathrm{CH}_{2} \mathrm{Cl}_{2}(50 \mathrm{~mL})$. The mixture was allowed to reflux for about $10-15 \mathrm{~h}$. Most $\mathrm{CH}_{2} \mathrm{Cl}_{2}$ was separated by distillation, and the resulting material was dissolved in EtOAc (50 $\mathrm{mL})$. The organic layer was poured into $\mathrm{NaHSO}_{3} 10 \%(3 \times 15 \mathrm{~mL})$, washed with brine, dried over $\mathrm{Na}_{2} \mathrm{SO}_{4}$, evaporated to dryness, to yield 3,4-dimethoxyphenyl formate (5) as a pale-red oil $(83.5 \%)$; IR (KBr, cm $\left.{ }^{-1}\right): 3087,3074,3.006,2959,2939,2913,2875,2838$ $(\mathrm{O}=\mathrm{C}-\mathrm{H}), 1738(\mathrm{C}=\mathrm{O}), 1266(\mathrm{C}-\mathrm{O}-\mathrm{C}), 1026$ (C-O-C), 867; ${ }^{1} \mathrm{H}$ NMR $\left(\mathrm{CDCl}_{3}, 200 \mathrm{MHz}\right) \delta: 8.29$ (s, 1H, OOC-H), 6.86 (d, 1H, H-Ar), 6.67 (s, $2 \mathrm{H}$, broad, $\mathrm{H}-\mathrm{Ar}), 3.87$ (s, $\left.3 \mathrm{H}, \mathrm{OCH}_{3}\right), 3.83\left(\mathrm{~s}, 3 \mathrm{H}, \mathrm{OCH}_{3}\right) ;{ }^{13} \mathrm{C}$ $\mathrm{NMR}\left(\mathrm{CDCl}_{3}, 50 \mathrm{MHz}\right) \delta: 159.7(\mathrm{OCOH}), 149.6\left(\mathrm{C}-\mathrm{OCH}_{3}\right), 147.3$ (C-OCHO), $143.6\left(\mathrm{C}-O C H_{3}\right), 112.4\left(\mathrm{H}-\mathrm{C}_{\mathrm{ar}}\right), 111.3\left(\mathrm{H}-\mathrm{C}_{\mathrm{ar}}\right), 105.3$ $\left(\mathrm{H}-\mathrm{C}_{\mathrm{ar}}\right), 56.2\left(\mathrm{OCH}_{3}\right), 56.1\left(\mathrm{OCH}_{3}\right)$.

Afterwards, the crude product (5) was dissolved in $\mathrm{MeOH}(5$ $\mathrm{mL})$, under $\mathrm{N}_{2}$ atmosphere. Then, a solution of $\mathrm{KOH} 10 \%(10 \mathrm{~mL})$ was added dropwise, allowing basic hydrolysis of (5). The mixture was poured into $\mathrm{HCl} 5 \%(5-15 \mathrm{~mL})$ and extracted with EtOAc (3 x $15 \mathrm{~mL})$, being washed with brine $(3 \times 10 \mathrm{~mL})$, dried over $\mathrm{Na}_{2} \mathrm{SO}_{4}$, evaporated to dryness, to yield 3,4-dimethoxyphenol (6) as a red oil (61\%, from 15); IR (KBr, cm $\left.{ }^{-1}\right): 3396(\mathrm{O}-\mathrm{H}), 3087,3044,3003,2959$, 2938, 2835, 1224 (C-O-C), 1025 (C-O-C), 835; ${ }^{1} \mathrm{H}$ NMR ( $\mathrm{CDCl}_{3}$, $200 \mathrm{MHz}) \delta: 6.73$ (d, J=8 Hz, 1H, H-Ar), 6.47 (s, 1H, H-Ar), 6.36 (d, J=8 Hz, 1H, H-Ar), 3.81 (s, $\left.3 \mathrm{H}, \mathrm{OCH}_{3}\right), 3.81$ (s, $\left.3 \mathrm{H}, \mathrm{OCH}_{3}\right) ;{ }^{13} \mathrm{C}$ $\mathrm{NMR}\left(\mathrm{CDCl}_{3}, 50 \mathrm{MHz}\right) \delta: 150.4\left(\mathrm{C}-\mathrm{OCH}_{3}\right), 150.0\left(\mathrm{C}-\mathrm{OCH}_{3}\right), 143.2$ $(\mathrm{C}-\mathrm{OH}), 112.7\left(\mathrm{H}-\mathrm{C}_{\mathrm{ar}}\right), 106.0\left(\mathrm{H}-\mathrm{C}_{\mathrm{ar}}\right), 100.8\left(\mathrm{H}-\mathrm{C}_{\mathrm{ar}}\right), 56.7\left(\mathrm{OCH}_{3}\right)$, $55.9\left(\mathrm{OCH}_{3}\right)$.

\section{Preparation of 1,2,4-Trimethoxybenzene (3)}

In a three-neck round bottom flask with a reflux condenser, a suspension of crude 3,4-dimethoxyphenol (6) (500 mg; $3.29 \mathrm{mmol}$ ) and $\mathrm{K}_{2} \mathrm{CO}_{3}(987 \mathrm{mg} ; 7.14 \mathrm{mmol})$ in anhydrous $\mathrm{CH}_{3} \mathrm{COCH}_{3}(30 \mathrm{~mL})$ was stirred at $40-45^{\circ} \mathrm{C}$, under argonium atmosphere. After $1 \mathrm{~h}, \mathrm{CH}_{3} \mathrm{I}$ (1.41 g; $0.62 \mathrm{~mL} ; 9.74 \mathrm{mmol})$ was added dropwise and the resulting mixture was refluxed for $7 \mathrm{~h}$.

The solvent was then removed under reduced pressure and the resulting oil was poured into $\mathrm{HCl} 5 \%(10 \mathrm{~mL})$, and extracted with EtOAc $(3 \times 20 \mathrm{~mL})$. The organic layer was then washed with brine, dried over $\mathrm{Na}_{2} \mathrm{SO}_{4}$, evaporated to dryness, and purified by silica gel chromatography (5\% EtOAc/hexanes) to yield 1,2,4-trimethoxybenzene (3) as an oil (97\%); IR (KBr, cm-1): 3081, 2998, 2938, 2908, 2834, 1230 (C-O-C), 1027 (C-O-C), 834; ${ }^{1} \mathrm{H}$ NMR ( $\mathrm{CDCl}_{3}, 200$ MHz) $\delta: 6,79$ (d, $J=8 \mathrm{~Hz}, 1 \mathrm{H}, \mathrm{H}-\mathrm{Ar}) ; 6,52$ (d, $J=3 \mathrm{~Hz}, 1 \mathrm{H}, \mathrm{H}-\mathrm{Ar})$; 6.39 (dd, $J=3 \mathrm{~Hz}, J=8 \mathrm{~Hz}, 1 \mathrm{H}, \mathrm{H}-\mathrm{Ar}), 3.86\left(\mathrm{~s}, 3 \mathrm{H}, \mathrm{OCH}_{3}\right), 3.83$ (s, $\left.3 \mathrm{H}, \mathrm{OCH}_{3}\right), 3.77\left(\mathrm{~s}, 3 \mathrm{H}, \mathrm{OCH}_{3}\right) ;{ }^{13} \mathrm{C} \mathrm{NMR}\left(\mathrm{CDCl}_{3}, 50 \mathrm{MHz}\right)$

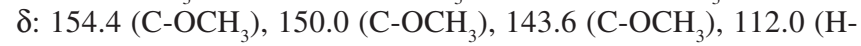
$\left.\mathrm{C}_{\mathrm{ar}}\right), 103.0\left(\mathrm{H}-\mathrm{C}_{\mathrm{ar}}\right), 100.5\left(\mathrm{H}-\mathrm{C}_{\mathrm{ar}}\right), 56.6\left(\mathrm{OCH}_{3}\right), 55.9\left(\mathrm{OCH}_{3}\right), 55.8$ $\left(\mathrm{OCH}_{3}\right)$; HRMS $\left.m / z, \%\right): 168.078550$ (68.4). Calc. for $\mathrm{C}_{10} \mathrm{H}_{14} \mathrm{O}_{3}$ : 168.078644 .

\section{RESULTS AND DISCUSSION}

Indol (1) and 1,2,4-trimethoxybenzene (3) are volatile substances, known as flower semiochemicals. ${ }^{3}$ The mixture of these substances with vanillin (2), named TIV mixture, was tested in a citrous orchard (of about $120 \times 15 \mathrm{~m}$ ), in a preliminary study for evaluating the insect reponses to traps (Mc Phail type one from Biocontrole ${ }^{\circledR}$ ) baited with it.

The vanillin (2) was chosen to be part of the mixture of semiochemicals used herein because is a low cost compound and also was found in the floral essential oil of sixteen Clusia species and one of the main components of the scent profile detectable by human nose used by moths pollination in Struthiola ciliate (Thymelaceae). ${ }^{7,8}$ 


\section{TIV mixture}

The mixture called TIV (Figure 1) is formed by the semiochemicals indol (1), vanillin (2), both were purchased, and 1,2,4-trimethoxybenzene (3), which has been synthetized in our laboratory from 2 in a low cost and fast route (Figure 2).<smiles>c1ccc2[nH]ccc2c1</smiles>

(1)<smiles>COc1cc(C=O)ccc1O</smiles>

(2)<smiles>COc1ccc(OC)c(OC)c1</smiles>

(3)
Figure 1. Semiochemicals in the TIV mixture

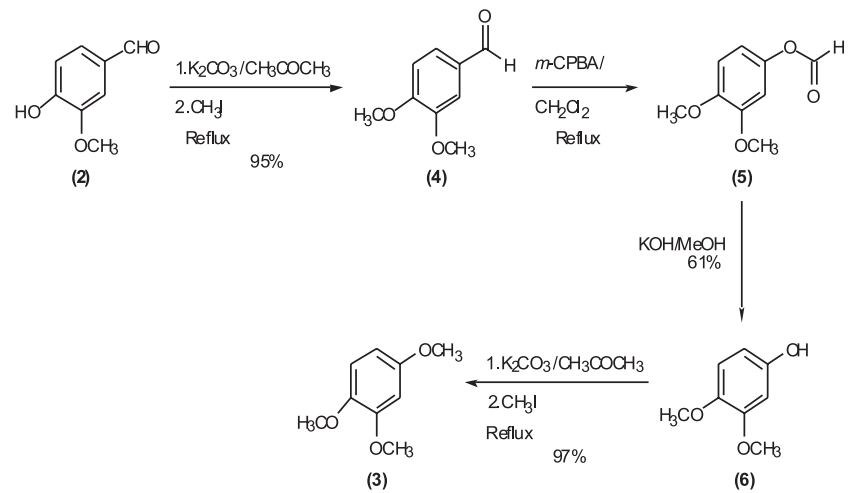

Figure 2. Synthetic approach for the preparation of 1,2,4-trimethoxybenzene (3) from vanillin (2)

Our synthetic approach for the preparation of $\mathbf{3}$ started with the methylation of vanillin (2), by treatment with methyl iodide $\left(\mathrm{CH}_{3} \mathrm{I}\right)$ in the presence of $\mathrm{K}_{2} \mathrm{CO}_{3}$, in $\mathrm{CH}_{3} \mathrm{COCH}_{3}$ under reflux, to obtain the 3,4-dimethoxybenzene (4) in $95 \%$ yield.

The next step was the oxidation of the carbonylic carbon of the 3,4-dimethoxybenzaldehyde (4). For this purpose, in our hands different reactional oxidation conditions, employing $\mathrm{H}_{2} \mathrm{O}_{2}$ or $m$-CPBA, as the oxidant agents were carried out without a synthetic success. However, the best result was obtained when 3,4-dimethoxybenzaldehyde (4) was treated with $m$-CPBA in $\mathrm{CH}_{2} \mathrm{Cl}_{2}$, in a buffered reaction mixture with $\mathrm{NaHCO}_{3}$, to form 3,4-dimethoxyphenyl formate (5). The synthetic approach described herein is more practical and versatile than others from literature. ${ }^{9-14}$ Afterwards, $\mathbf{5}$ was treated under basic hydrolysis conditions in $\mathrm{KOH} / \mathrm{MeOH}$, to obtain 3,4-dimethoxyphenol (6) in $61 \%$ yield from 4.

Phenol derivative 6 was methylated by $\mathrm{CH}_{3} \mathrm{I}$ in $\mathrm{K}_{2} \mathrm{CO}_{3} / \mathrm{CH}_{3} \mathrm{CO}-$ $\mathrm{CH}_{3}$, to yield 3 in $97 \%$. Therefore, the global yield of the synthesis of $\mathbf{3}$ was $56 \%$, which was satisfying to our aim.

All compounds were characterized through IR, ${ }^{1} \mathrm{H}$ NMR, ${ }^{13} \mathrm{C}$ NMR analysis.

\section{Insects attracted by TIV mixture in citrous orchard - preliminary field experiments}

Mc Phail traps containing TIV mixture were installed in a domestic citrous orchard in Bom Jesus Farm, at Silva Jardim, in the state of Rio de Janeiro, Brazil. In this type of trap, the insects are attracted not only by the odour stimulus (semiochemical mixture) but also by a visual sign, by the inferior yellow piece of the trap. Once inside the trap, the insects are not able to escape because they fly towards the superior colorless piece. Therefore, without food and energy, they die being collected in the Mc Phail traps.
After 7 days of exposition, 4 species of insects were captured and sent to identification at University of Sao Paulo (Departamento de Biologia, Faculdade de Filosofia, Ciências e Letras de Ribeirão Preto). None insect captured was observed in the blank traps. In Table 1, we list the 4 species attracted by TIV mixture in the citrous orchard preliminary test.

Table 1. Field experiment results

\begin{tabular}{lccc}
\hline SPECIES & \multicolumn{3}{c}{ TRAPS } \\
\hline & Average & Total & Blanks \\
\hline Eulaema nigrita Lepeletier, 1841 & 4.33 & 26 & - \\
Euglossa pleosticta Dressler, 1982 & 15.83 & 95 & - \\
$\begin{array}{l}\text { Euglossa securigera Dressler, 1982 (sensu } \\
\text { Moure) }\end{array}$ & 0.33 & 2 & - \\
Euglossa sp. aff. Sapphirina Moure, 1968 & 0.5 & 3 & -
\end{tabular}

All insects attracted by the TIV mixture belong to the most important genus of Euglossini tribe: Eulaema sp and Euglossa sp.

Euglossine bees (Apidae: Euglossini) are an important exclusively neotropical pollinator group that are most closely related with certain angiosperm families. Without specifically trying to collect pollen, they are able to secure pollination of species of Caesalpiniaceae, Maranthaceae, Euphorbiaceae, Araceae, Gesneriaceae, Bignoniaceae, Orchidaceae and others. ${ }^{15}$ They are known as orchid bees.

Male euglossine bees are the only pollinators of some orchids, e.g. Gongora, Castasctum, and Coryanthes. They are attracted to the essences produced by these orchids' flowers. The use of these essences is not so well understood, but they may be used as a sexual attractant. ${ }^{15}$

Euglossine bees are described as a group of brightly colored tropical insects. Many species are green, blue, purple, gold, or red. However, in the Eulaema genus, the insects are bigger with less metallic bright bodies. They have tongues that, in some species, may be twice as long as the body. The long tongue allows them to reach nectar in deep-throated tropical flowers. Many species of orchid bees collect nectar, pollen, and other substances from orchids. ${ }^{16}$

Our mixture of semiochemicals (TIV) captured 4 species of euglossine bees (Table 2): Eulaema nigrita Lepeletier (1841), Euglossa pleosticta Dressler (1982), Euglossa securigera Dressler (1982), sensu Moure and Euglossa sp. aff. Sapphirina Moure (1968).

Eulaema nigrita and Euglossa pleosticta were the most attracted species in the tested conditions, with 21 and $75 \%$, respectively (Figure 3).

Eulaema nigrita is an important natural pollinator of Passiflora $s p$. The natural fertilization of its flowers is rare due to the autoincompatibility, yielding small fruits with few seeds. The pollinization in the commercial crops of Passiflora sp. is naturally done by insects of Eulaema and Xylocopa species or artificially, by men.

Euglossa sp. are important in the orchid pollinization. Those flowers are cultivated due to their fragrances and exotic beauty. Thus, all insects captured may have commercial importance. We propose TIV mixture application in orchid cultivation and Passiflora sp. crops in aim to increase the population of pollinizators in these areas, and therefore improve the production of flowers and fruits. Of course, traps would not be allowed for these purposes in order to avoid insect death.

\section{Volatilization test in laboratory of TIV mixture - preliminary test}

A preliminary volatilization test was carried out in our laboratory in order to establish the optimum conditions to evaluate de kinetics of liberation of the semiochemicals from the traps. Seven days samples adsorbed in the Tenax ${ }^{\circledR}$ resin were subjected to CG-DIC (Figure 4) and GC-MS 


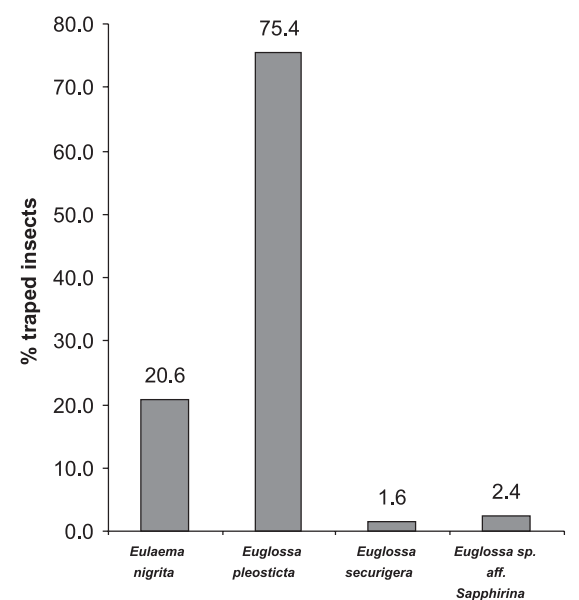

Figure 3. Euglossine bees attracted in field experiments

analysis (data not shown). This preliminary study indicated the presence of indol (49\%), 1,2,4-trimethoxybenzene (49\%) and vanillin (2\%).

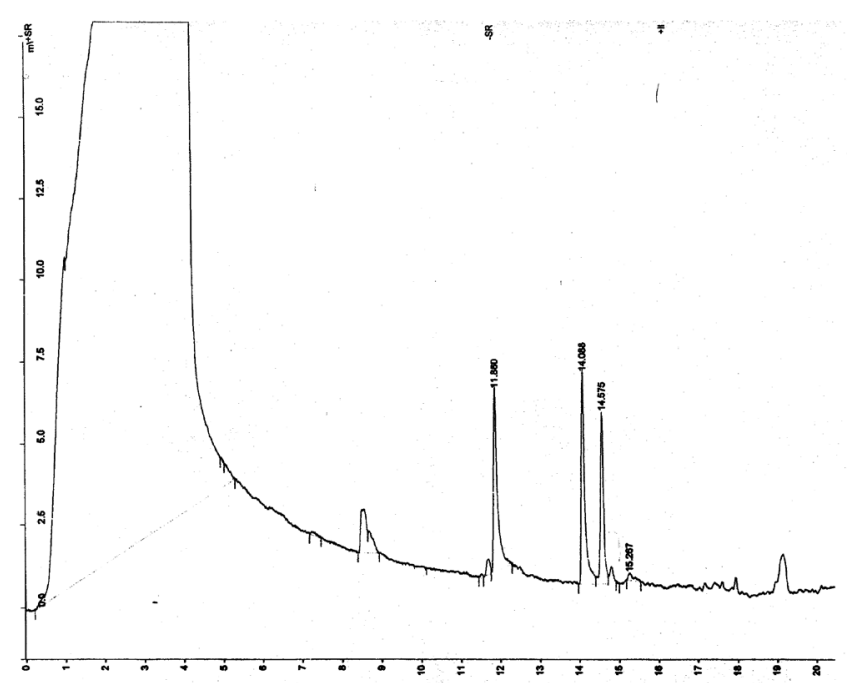

Figure 4. GC-FID chromatogram of TIV mixture volatiles

\section{CONCLUSIONS}

Employing a low cost approach, we synthesized 1,2,4-trimethoxybenzene (3) in 56\% overall yield, after a long study to determine the optimum conditions to prepare 6 from 4.

The preliminary field study in citrous orchard, located at Bom Jesus Farm in Silva Jardim, in the state of Rio de Janeiro, in Brazil, showed promising results in attracting insects by TIV mixture. Pollinators (orchid bees) were captured, specially Eulaema nigrita Lepeletier, 1841 e Euglossa pleosticta Dressler, 1982, both of them are important in the Passiflora sp. crops and orchid cultivars, respectively. In this way, TIV mixture may be used in those crops or cultivars to increase the population of pollinators in those areas.

The preliminary study of the volatilization of TIV indicated the presence of indol (about 49\%), 1,2,4-trimethoxybenzene (49\%) and vanillin $(2 \%)$.

A field study of the substituted derivatives at the 3-position of 1,2,4-trimethoxybenzene (3), which will be done by directed metalation strategy ${ }^{17}$ to be evaluated their potential as insect attractants as well as the contribution of each TIV mixture constituent to attract insects will be a future work. We also intend to determine the optimum mixture proportions to each of one these compounds.

\section{ACKNOWLEDGEMENTS}

We thank CAPES, CNPQ, FAPERJ and FUJB for the financial support.

\section{REFERENCES}

1. Cox, P. D.; Collins, L. E.; J. Stor. Prod. Res. 2002, 8, 95.

2. Pickett, J. A.; Wadhams, L. J.; Woodcock, C. M.; Agr. Ecosyst. Environ. 1997, 64, 149.

3. Ventura, M. U.; Martins, M. C.; Pasini, A.; Florida Entomol. 2000, 83, 403.

4. Perrin, D. D.; Armarego, W. L.; Purification of Laboratory Chemicals, $3^{\text {rd }}$ ed., Butterworth-Heinemann Ltd.: London, 1988.

5. Williamson, K. L.; Macroscale and Microscale Organic Experiments, $3^{\text {rd }}$ ed., Houghton Mifflin Company: Boston, 1999.

6. Still, W. C.; Kahn, M.; Mitra, A.; J. Org. Chem. 1978, 43, 2923.

7. Nogueira, P. C. L.; Bittrich, V.; Shepherd, G. J.; Lopes, A., V.; Marsaioli, A. J.; Phytochemistry 2001, 56, 443.

8. Makhoela, T.; Manning, J. C.; South Afr. J. Bot. 2006, 72, 597.

9. Wriede, U.; Fernandez, M.; West, K. F.; Harcourt, D.; Moore, H. W.; J. Org. Chem. 1987, 52, 4485.

10. Hardegger, E.; Steiner, K.; Corrodi, W. E.; Schmidt, Th.; Knoepfel, H. P.; Rieder, W.; Kugler, F.; Gempeler, H.; Helv. Chim. Acta 1964, 47, 1996.

11. Dickstein, J. S.; Mulrooney, C. A.; O’Brien, E. M.; Morgan, B. J.; Kozlowski, M. C.; Org. Lett. 2007, 9, 2441.

12. Guzman, J. A.; Mendoza, V.; Garcia, E.; Garibay, C. F.; Olivares, L. Z.; Maldonado, L. A.; Synth. Commun.1995, 25, 2121.

13. Spyer, L.; Kloc, K.; Mlochowski, J.; J. Prakt. Chem. 1985, 327, 808.

14. Belleau, B.; Weinberg, N. L.; J. Am. Chem. Soc. 1963, 85, 2525.

15. Brito, C. M. S.; Rêgo, M. M. C.; Braz. J. Biol. 2001, 61, 631.

16. Roubik, D. W.; Hanson, P. E.; Abejas de orquídeas de la América tropical: Biología y Guía de Campo, $1^{\mathrm{a}}$ ed., Instituto Nacional de Biodiversidade: Santo Domingo de Heredia, 2004.

17. Slocum, D. W.; Dumbris, S.; Brown, S.; Jackson, G.; Lamastus, R.; Mullins, E.; Ray, J.; Shelton, P.; Walstrom, A.; Wilcox, J. M.; Holman, R. W.; Tetrahedron 2003, 59, 8275. 